\title{
Tracking of the development wear of cutting tools with different geometry during parting-off
}

\author{
Robert Čep ${ }^{1,}$, Šárka Malotová1, Tomáš Zlámal ${ }^{1}$, Vladimír Vrba ${ }^{1}$ and Marian Borzan ${ }^{2}$ \\ ${ }^{1}$ Faculty of Mechanical Engineering, VŠB-TU Ostrava, 17. listopadu 15/2172, Ostrava-Poruba, 70833 , \\ Czech Republic \\ ${ }^{2}$ Faculty of Machine Building, Technical University of Cluj-Napoca, Memorandumului street, nr. 28, \\ Cluj-Napoca, 400114, Romania
}

\begin{abstract}
The article deals with the tracking of the wear development of cutting tools made from sintered carbide during parting-off of steel $\mathrm{C} 45$ (ČSN 12 050.1). For experiment were selected inserts from two producers of cutting tools with different geometry. The parting-off was realized in the workpiece axis and the whole experiment was divided into two parts, parting-off to zero and parting-off to pre-drilled hole into material. The experiment was evaluated on the principle direct microscopic method and was observed the wear on the flank of cutting tool VBB. Tests were realized in cooperation with Pramet Tools Šumperk, Czech Republic.
\end{abstract}

\section{Introduction}

Parting-off is one of the special turning methods, where is required special cutting tools. The aim of every process of machining is to achieve the best results in terms of the quality of surface and the durability of the cutting tools. During parting-off is payed attention especially to toughness and strength of tool and formation and leaving of chip. Parting-off of bigger diameter of workpieces or production of deeper grooves can cause very strong vibrations, which influence surface and lifetime of cutting tool. This is associated with chip formation, when unsuitable formation the chip winds up on cutting tool and damages it. During parting off is very important to become conscious of the cutting tool moves from maximal diameter to its axis, where the cutting speed is zero and after separation of the component, a small pin was created (figure 1). [1,2]

Grooving or parting-off cutting tools are designed in different shapes and geometry with respect to build up edge, which is typical mechanism of wear for these methods. Creation of build up edge is confirmed for machining of softer materials, like as steel C45. The build up edge causes pulling up of the parts of cutting tool. The wear on the flank and creation of the groove on the rake are caused by high cutting speed. For parting-off is important to set up suitable entry conditions (e.g. width of cutting tool, clamping, type of inserts or cooling), which ensures durability and quality of surface. [2, 3]

\footnotetext{
${ }^{*}$ Corresponding author: robert.cep@vsb.cz
} 


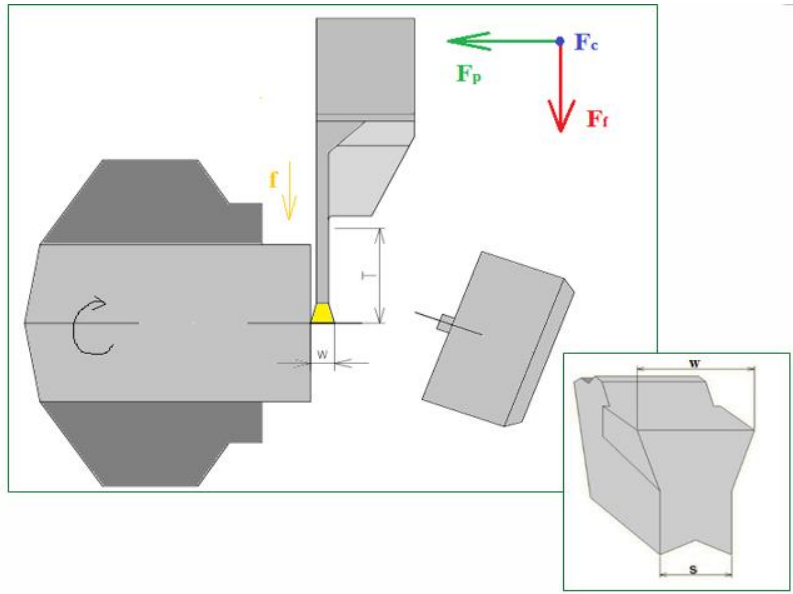

Fig. 1. Parting-off [2].

\section{Design of experiment}

Experimental part was focused on the tracking of behaviour wear of cutting tool with different geometry during parting-off of material C45 (ČSN 12 050.1) about diameter $80 \mathrm{~mm}$. The inserts were made from sintered carbide, width $\mathrm{w}=3 \mathrm{~mm}$, from producer Pramet Tools and Iscar (table 1). The insert marked G362-AA-U02-P14 is designed with bevel and is suitable for production grooves with mechanical stress and parting-off during high cutting speeds, where is not the creation of build up edge. Tested ISCAR inserts are designed with bevel and without it and with different geometry. For all type of inserts were tested two samples due to statistical evaluation. All cutting tools were clamped into blade (ISO X). The clamping was ensured by cutting force into self-locking bed. During parting - off was used cooling for smoother machining.

Table 1. Tested inserts [4].

\begin{tabular}{|c|c|c|c|c|c|c|c|}
\hline Producer & Insert & $\begin{array}{c}\text { Geomet } \\
\text { ry }\end{array}$ & Grade & Substrate & Coating & Sample & Figure \\
\hline \multirow{5}{*}{ Pramet } & $\begin{array}{c}\text { LCMR } \\
031602\end{array}$ & $\mathrm{CM}$ & $\mathrm{T} 8330$ & 087 & P523 & A1, A2 & \\
\cline { 2 - 8 } & $\begin{array}{c}\text { G362- } \\
\text { AA- } \\
\text { U02- } \\
\text { P14 }\end{array}$ & P14 & T8330 & 087 & P523 & $\begin{array}{c}\text { B1, B2/ } \\
\text { E1, E2 }\end{array}$ & development \\
\hline \multirow{5}{*}{ ISCAR } & $\begin{array}{c}\text { DGN } \\
\text { 3102J }\end{array}$ & J & IC808 & - & - & C1, C2 & \\
\cline { 2 - 8 } & DGN & C & IC808 & - & - & D1, D2 / & \\
\hline
\end{tabular}

Due to previous tests, when there was not significant wear for cutting tools above or below workpiece axis, cutting edge was set up into the workpiece axis. The experiment was 
divided into two parts - parting-off to zero diameter of workpiece and for parting-off with pre-drilled hole.

\subsection{Parting-off to zero (ø $80 \mathrm{~mm}-0 \mathrm{~mm}$ )}

For the economic point of view, for the both cases were designed procedure of parting-off for one cycle (figure $2 \mathrm{a}$ parting-off to zero and figure $2 \mathrm{~b}$ parting-off with pre-drilled hole). In table 2 there are cutting conditions. Feed rate and width of cutting tool was constant. Due to designed cycle of parting-off was wear measured in interval $t_{\mathrm{As}}=2,5 \mathrm{~min}$

Table 2. Cutting conditions.

\begin{tabular}{|c|c|c|c|}
\hline \multicolumn{4}{|c|}{ Cutting conditions - parting-off to zero } \\
\hline \multicolumn{2}{|c|}{ Ø $80-\varnothing 25 \mathrm{~mm}$} & \multicolumn{2}{|c|}{ Ø $25-\varnothing 0 \mathrm{~mm}$} \\
\hline $\mathrm{V}_{\mathrm{c}}\left[\mathrm{m} \cdot \mathrm{min}^{-1}\right]$ (const.) & 180 & $\mathrm{n}\left[\mathrm{min}^{-1}\right]$ (const.) & 2300 \\
\hline $\mathrm{f}[\mathrm{mm}]$ & 0,14 & $\mathrm{f}[\mathrm{mm}]$ & 0,14 \\
\hline $\mathrm{w}[\mathrm{mm}]$ & 3 & $\mathrm{w}[\mathrm{mm}]$ & 3 \\
\hline
\end{tabular}

\subsection{Parting-off with pre-drilled hole}

To exclude the impact of the build up edge testing was with modified semi-finished product. In axis of workpiece was pre-drilled hole of diameter $20 \mathrm{~mm}$, so that cutting speed was constant. Due to save material and time consuming, the tests were tested with using cutting tools marked G362-AA-U02 a DGN 3102 C. Process diagram is shown in figure $2 \mathrm{~b}$. The cutting conditions were set up the same like as previous case, when cutting speed was $180 \mathrm{~m}$ - $\mathrm{min}^{-1}$, feed rate $0,14 \mathrm{~mm}$ and width of cutting tools $3 \mathrm{~mm}$. The wear was measured in interval $\mathrm{t}_{\mathrm{As}}=3,5 \mathrm{~min}$ after twenty grooves.
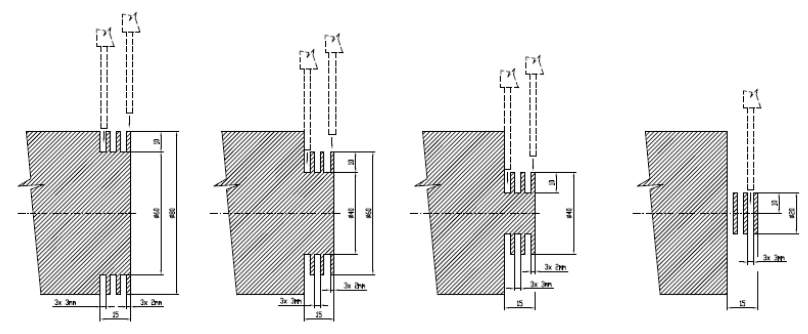

a)

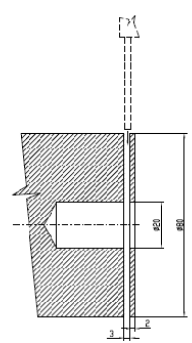

b)

Fig. 2. a) Diagram of parting-off to zero b) Diagram of parting-off with pre-drilled hole.

\section{Results and Evaluation}

For evaluation of wear was used direct microscopic method. The wear size was determined by direct measuring of linear dimensions in different time intervals for parting-off to zero and pre-drilled hole. All measuring were realized by same ways. Critical value for flank wear was determined VBcrit $=0,2 \mathrm{~mm}$. When the critical wear or interval of machining $\mathrm{t}_{\mathrm{As}}=30$ min were reached, the tests were stopped and ended. In table 3, there are shown results for individual testing cutting tools. There is always shown the wear in final phase of parting-off to zero. 
Table 3. Parting-off to zero.

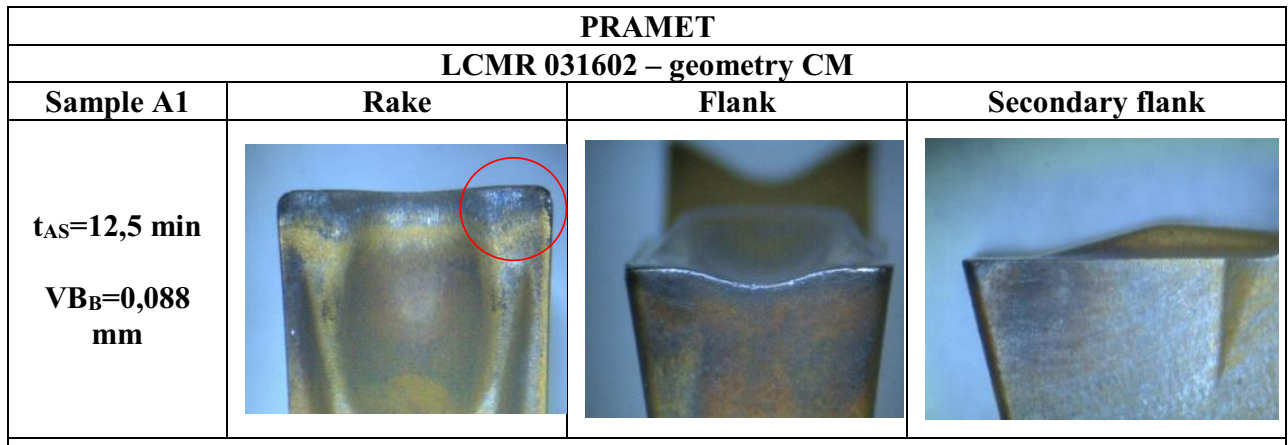

The samples A1 and A2 were poorly formed the chips. Visible wear of insert has emerged after 10 min in the cut. It was breaking off of cutting edge and damage of secondary flank. Sample A2 was damaged due to the created build up edge on the cutting edge and the test was stopped.

\begin{tabular}{|c|c|c|c|}
\hline \multicolumn{4}{|c|}{ G362-AA-U02 - geometry P14 } \\
\hline Sample B1 & Rake & Flank & Secondary flank \\
\hline \multicolumn{4}{|l|}{$t_{A S}=5,1 \mathrm{~min}$} \\
\hline \multicolumn{4}{|l|}{$\begin{array}{c}\mathrm{VB}_{\mathrm{B}}=\mathbf{0 , 0 7 6} \\
\mathrm{mm}\end{array}$} \\
\hline \multicolumn{4}{|c|}{ ISCAR } \\
\hline \multicolumn{4}{|c|}{ DGN 3102J - geometry J } \\
\hline Sample C1 & Rake & Flank & Secondary flank \\
\hline \multicolumn{4}{|l|}{$t_{A S}=12,5 \mathrm{~min}$} \\
\hline $\begin{array}{c}\mathrm{VB}_{\mathrm{B}}=12,5 \\
\mathrm{~mm}\end{array}$ & & & \\
\hline & & & \\
\hline
\end{tabular}

Competitive inserts formed chip very good and the whole process was quiet. There was abrasion wear and a plastic deformation at 9 minutes in cut. The test could continue with this insert. Due to time difficulty the test was stopped.

\begin{tabular}{|c|c|c|c|}
\hline \multicolumn{4}{|c|}{ DGN 3102C - geometry C } \\
\hline Sample D1 & Rake & Flank & Secondary flank \\
\hline $\mathbf{t}_{\mathrm{AS}}=7,5 \mathrm{~min}$ & & & \\
\hline $\begin{array}{c}\mathrm{VB}_{\mathrm{B}}=\mathbf{0 , 0 5 4} \\
\mathrm{mm}\end{array}$ & & & \\
\hline
\end{tabular}

Again, the chip formed very good with using competitive inserts. It was same cutting tool, but with different geometry. The test was for the both samples $(\mathrm{C} 1, \mathrm{C} 2)$ prematurely stopped, because after 7 minutes the tip was damaged. 
Sample B1 poorly formed the chip and it was winded up to tool (figure 3). Test was prematurely stopped, because on the insert was mechanical damage after six minutes in cut. Development of wear for sample B2 was similar to previous inserts. There were cutting edge break off and test was prematurely stopped.

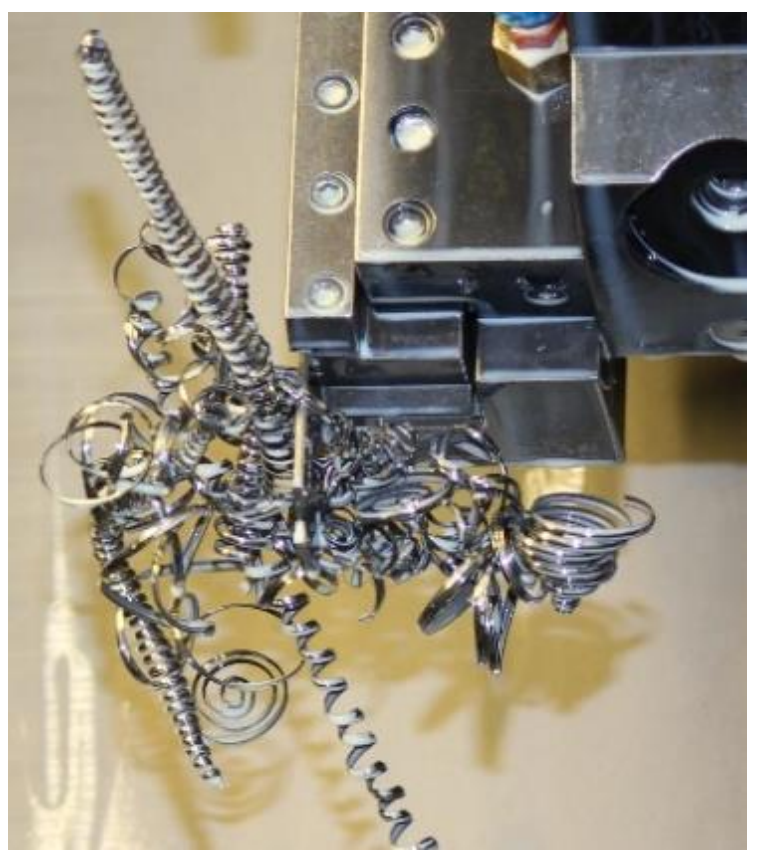

Fig. 3. Forming of the chip - sample B.

Figure 4 is shown graphical development of wear during parting-off to zero.

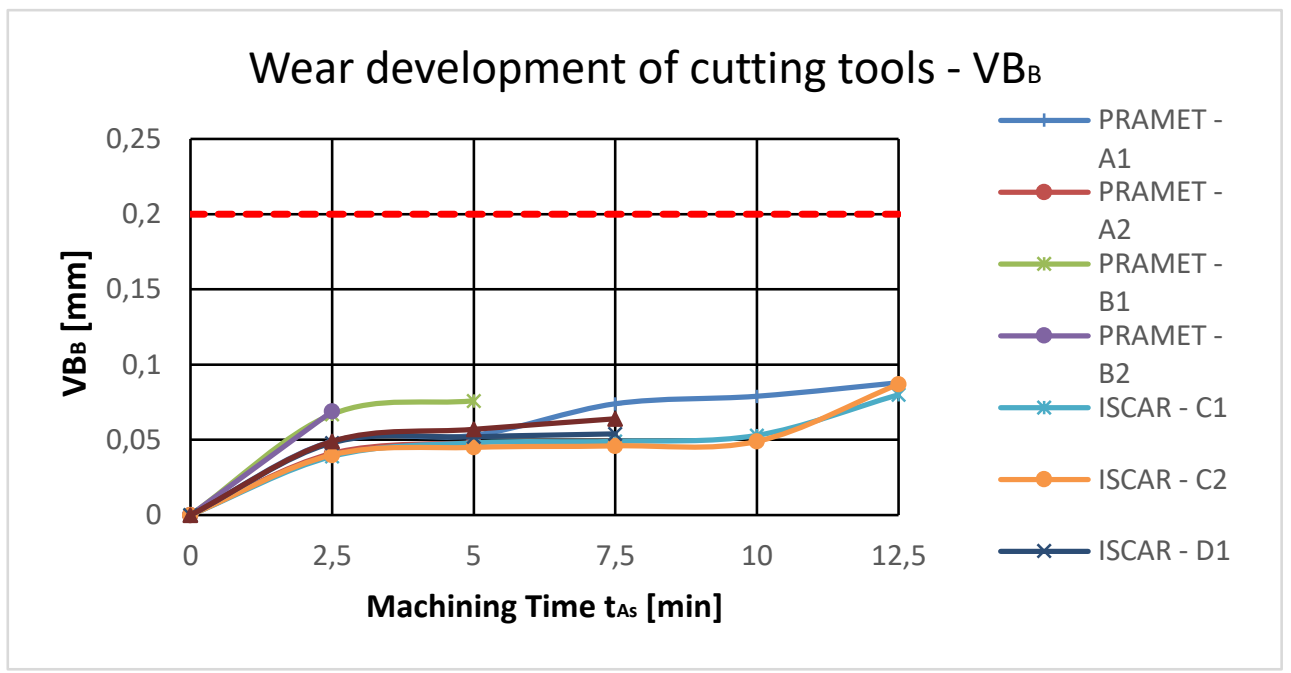

Fig. 4. Development of wear during parting-off to zero.

In table 4, there are results for testing cutting tools during parting-off to pre-drilled hole. Due to time difficulty were chosen two samples for testing (Pramet G362-AA-U02, Iscar DGN 3102C). 
Table 4. Parting-off to pre-drilled hole.

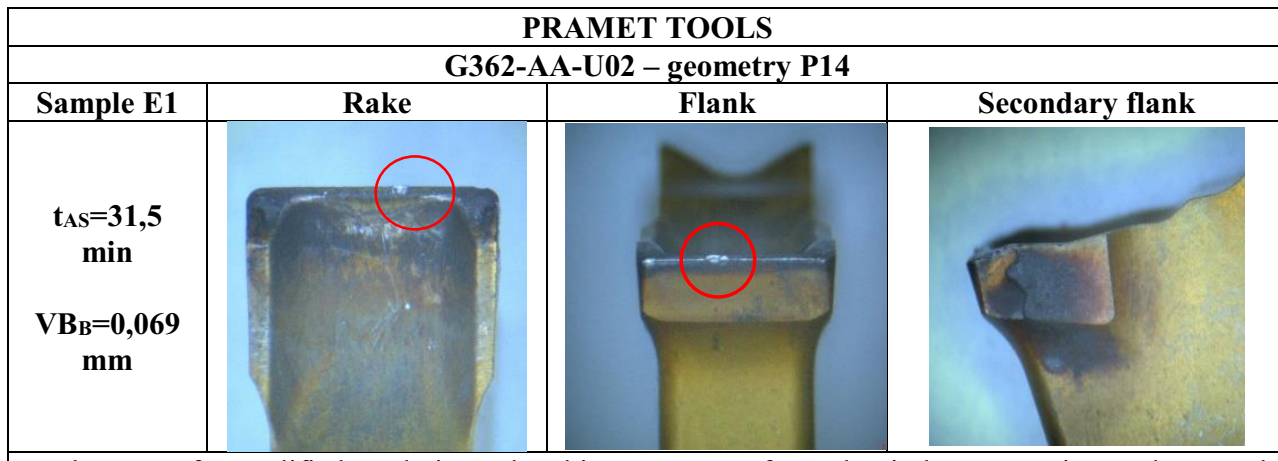

In the case of a modified workpiece, the chip was wrong formed, wind up to cutting tool, created tangled mass of machined material. Better chip forming was measured when cutting tool was deeper into workpiece.The test was stopped after half hour of machining, when was recorded small break off.

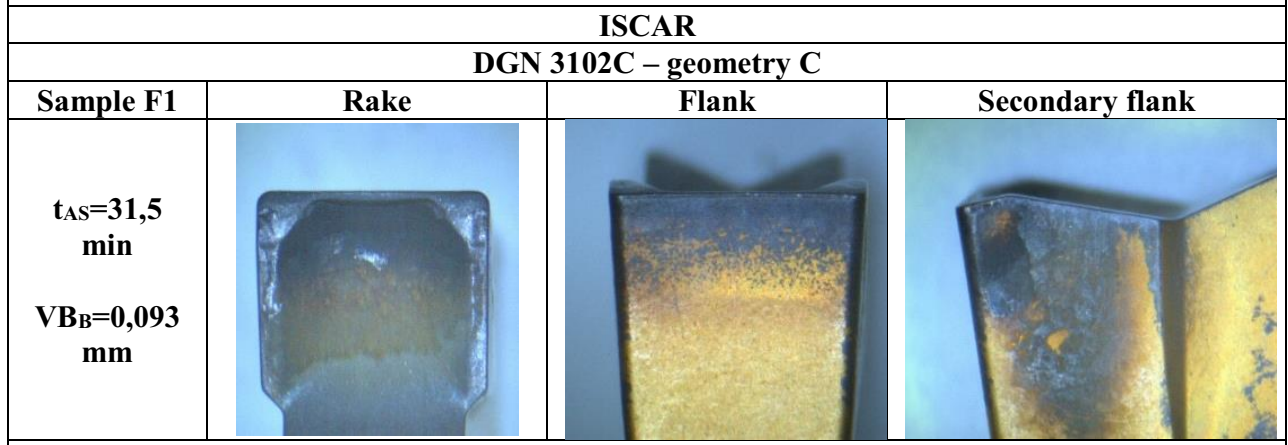

In the first third of the diameter, there was wrong chip forming, parting-off process was attended by excessive noise. Still, the process could continue, cutting edge was not damaged, but due to time difficulty the test was stopped.

Figure 5 is shown graphical development of wear during parting-off to pre-drilled hole.

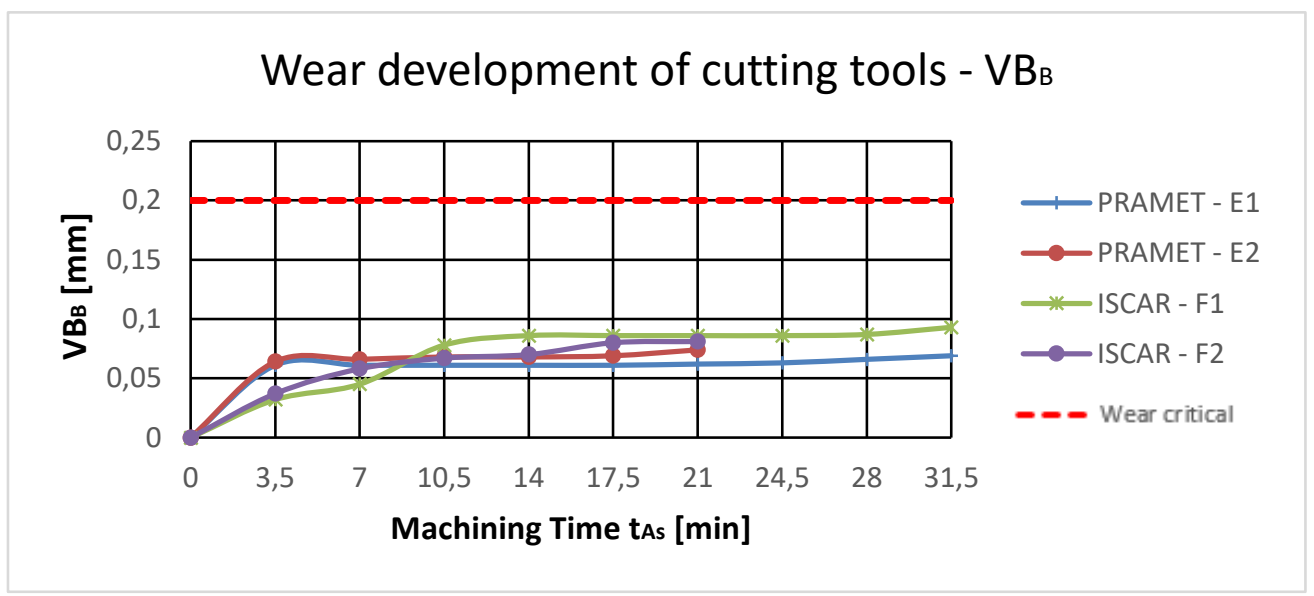

Fig. 5. Development of wear during parting-off to pre-drilled hole. 


\section{Conclusion}

The aim of experiment was found out behaviour of removable cutting inserts made from sintered carbide during parting-off into axis workpiece. The experiment was divided into two parts, first was the evaluation the wear during parting-off to zero and parting-off to pre-drilled hole of diameter $20 \mathrm{~mm}$. With decreasing diameter, decrease cutting speed and at this moment is danger of build up edge. The cutting tools were selected from offer firm Pramet Tools and Iscar.

The Pramet cutting tools with geometry CM stayed in the cut approximately 13 minutes. After ending test was measured visible break off of cutting edge, which was caused by build up edge. It is typical mechanism for parting-off during small cutting speed. The insert with geometry P14 formed long chip, which winded up to cutting tool and holder and caused damage cutting edge and the tests were stopped. Competitive inserts made by ISCAR with geometry $\mathrm{J}$ formed chip very good and had quiet process. The both samples $(\mathrm{C} 1, \mathrm{C} 2)$ stayed in the cut 13 minutes and wear was determined like as abrasive on the flank. Due to time difficulty teste were stopped, but these inserts could continue in parting-off. The inserts wit geometry $\mathrm{C}$ had wrong wear development. On the first sample D1 with this geometry had break off on the cutting edge due to build up edge. The test with sample D2 was prematurely stopped, the insert ceased form. The samples G362-AA-U02-P14 (PRAMET) a DGN 3102$\mathrm{C}$ (ISCAR) has bevel, which has a role to improve of inserts properties. In conditions of parting-off to zero (low cutting speed) vigorously decrease their durability. Machined material sticks on the insert and is created build up edge, which caused damage of cutting edge and prematurely stopped tests. Due to this reason these inserts were chosen for partingoff to pre-drilled hole, where cutting speed is still constant. The both cutting tools had very similar wear development. From the start of parting-off the chip wrong formed, this problem was removed after cut into workpiece and the whole process was quiet. The both type of inserts stayed in cut over the 30 minutes, then tests were stopped due to time and economic difficulty. The Pramet insert had visible break off of cutting edge, but it didn't influence its functionality. Competitive insert had very quiet process and better chip forming. The wear was only in abrasive form on the flank of cutting tool.

The experiment follows the recommendations, the grooves, where are shocks, dynamic stress and for parting-off outside the build up edge area (high cutting speed) is suitable used inserts with bevel.

Article has been done in connection with projects Education system for personal resource of development and research in field of modern trend of surface engineering - surface integrity, reg. no. CZ.1.07/2.3.00/20.0037 financed by Structural Founds of Europe Union and from the means of state budget of the Czech Republic and by project Students Grant Competition SP2016/172 and SP2016/174 financed by the Ministry of Education, Youth and Sports and Faculty of Mechanical Engineering VŠB-TUO.

\section{References}

1. T. Zlámal, J. Petrů, O. Vortel, M. Pagáč, P. Krajkovič, Adv. in Sci. and Tech. - Research J., Soc. Polish Mech. Eng. \& Techn., 10, 144-150, ISSN 2299-8624 (2016)

2. ŠS. Malotová, Contribution to the evaluation of the durability of cutting tools for partingoff of stainless steel, Thesis of Dissertation, Ostrava, VŠB - Technical university of Ostrava, 26 (2017)

3. $* * *$ http://www.productionmachining.com/articles/five-process-security-tips-whenparting-off

4. J. Veselovský, Tracking of the Type and Development of the Wear Insert During Grooving, Diploma Thesis, Ostrava, VŠB - Technical University of Ostrava, 79 (2016) 
